\title{
ORGANISATIONAL NORMS OF ACADEMIC ADMINISTRATION AT A HIGHER EDUCATION INSTITUTION
}

\author{
Prof FW Struwig: Director - School of Management Sciences, Nelson Mandela Metropolitan \\ University,
}

\section{Prof EE Smith: Associate Professor - Department of Business Management, Nelson Mandela Metropolitan University}

\begin{abstract}
This article sets out to investigate the organisational norms at a higher education institution as perceived by academic administrative staff members. To achieve the aim of this article, a literature study and empirical research were undertaken. A self-administered questionnaire was distributed to 88 staff members in the Academic Administration Department at a higher education institution. To investigate the relationship between the independent and dependent variables, nine hypotheses were tested. The results indicated significant relationships between some of these variables. Guidelines are provided as to which organisational norms are acceptable, which are not yet problematic but pose various challenges and which are problematic and need interventions. The guidelines could be useful in any organisational setting which requires new group formation or working relationships. A hypothesized model to investigate norms is also proposed.
\end{abstract}

\section{INTRODUCTION}

Various researchers (see for example Bray, 2008:692); Houston, 2008:61 and Biloslavo \& Trnavcevic, 2007:275) highlights the changing landscape of higher education and the challenges it poses to both management, staff and other stakeholders. Jongbloed, Enders and Salerno (2008:303) concur that higher education institutions need to consider their role in society and relationships with various stakeholder constituencies. Umashankar and Dutta (2007:54) is also of the opinion that "educational institutions of higher learning world-wide need to maintain their status and dignity in an environment of complex socio-economic pressures and changes in approaches to educational processes." This article focuses on the role of organisational norms in higher education institutions amidst the pressures and changes in the field of education. In this ever changing climate, excellent service delivery and client relationships are becoming more important to stay operationally efficient. To this end the Academic Administration Department is playing a vital role. According to Broersen and Van der Torre (2009:171), norms are being used in organisations to define the persistence of obligations of members and these norms come in varying forms, are used for various reasons and meant for varying domains. Schultz (2006:106) states that norms often carry an element of sanction - what consequences apply when behaviour is inappropriate. These norms often develop spontaneously and informally from the initial interactions in a group Firstly, the research objectives and restructuring of higher education institutions are outlined. A theoretical overview of organisational norms, the role of organisational demography and research hypotheses is also provided and the research methodology followed is highlighted. The results of the empirical study is presented and lastly, the main conclusions and recommendations.

\section{PROBLEM STATEMENT}

The changing landscape of higher education came about as a result of mergers which have taken place between various institutions. The mergers between various higher education institutions have brought about many changes, not only in the way things are done, but also to staffing structures. As a result many new working relationships and groups had to be formed. Organisational members were taken out of their former groups (for example they remained in the same section but had to move between various campuses) and placed in new groups. In a very short time period, members had to go through all the stages of group formation. The culture and norms of each of the previous institutions were different. Hatch and Cunliffe (2006:187) define norms as "the expression of values". They further state that norms are "the unwritten rules that allow members of a culture to know what is expected of them in a wide variety of situations including how to coordinate their behaviour with that of others". Often administrative staff is blamed for poor service delivery and not supporting academic structures in higher education institutions. As a result, the focus of this study was to investigate the perceptions of academic staff members regarding organisational norms, which might be an indication 
of certain behaviour patterns. This lead to the following research question to be addressed in this project:

To what extent did the changes in higher education facilitated group formation and group norms?

\section{OBJECTIVES}

The primary objective of this article is to investigate the organisational norms of the Department of Academic Administration at a higher education institution. To help achieve this objective, the following secondary goals are identified:

- To provide a literature overview of organisation norms and mergers of higher education institutions in South Africa.

- To empirically assess the organisational norms of the Administrative Department at a higher education institution.

- To provide guidelines for fostering norms in an organisation.

\section{THE MERGERS OF HIGHER EDUCATIONAL INSTITUTIONS IN SOUTH AFRICA}

The Government's proposal in the 1990s to change the institutional landscape in South Africa resulted in the restructuring of Higher Educational institutions. The current policy context for higher education follows a line from the National Commission on Higher Education (NCHE) to the Green Paper on Higher Education Transformation (1996), the Education White Paper (1997), the Higher Education Act of 1997 and the National Plan for Higher Education (2001). The principal aim in all these documents was to address the racial differentiation and discrimination which had created a divided and fragmented system wherein:

- resources were inequitably and inefficiently allocated;

- governance structures were undemocratic;

- access was highly skewed on racial lines;

- there was a lack of coordination, common goals or systematic planning; and

- there was an inability to respond to the economic and social needs of the majority of the population. (Department of Education, Green Paper, 1996: 10).

The National Plan for Higher Education in South Africa (2001) provided the framework and mechanisms for the restructuring of the higher education system to achieve the vision and goals for the transformation of the higher education system outlined in the Education White Paper (1997).

The Minister's goals and strategic objectives for transforming and restructuring the higher education landscape are summarised in Government Gazette (2002). The goals are:

- to increase access and to produce graduates with the skills and competencies necessary to meet the human resource needs of the country;

- to promote equity of access and outcomes and redress past inequalities through ensuring that student and staff profiles reflect the demographic composition of South African society;

- to ensure diversity in the institutional landscape of the higher education system through a mission and programme differentiation to meet national and regional skills and knowledge needs;

- to build high-level research capacity, including sustaining current research strength, as well as to promote research linked to national development needs; and

- to build new institutional identities and organisational forms through restructuring the institutional landscape of the higher education system, thus transcending the fragmentation, inequalities and inefficiencies of the apartheid past and to enable the establishment of South African institutions consistent with the vision and values of a non-racial, non-sexist and democratic society. (Government Gazette, 2002: 7)

According to the Minister's restructuring proposals, there are to be:

- 11 Universities, 2 of which would be expected to develop career-focused technikon-type programmes to address regional needs; 
- 5 Technikons;

- 6 Comprehensive Institutions, 4 of which would be established through the merger of a technikon and a university and 2 through the redevelopment and refocusing of an existing university; and

- 2 National Institutes for Higher Education (Government Gazette, 2002).

\section{REFLECTIONS ON THE MERGERS OF HIGHER EDUCATIONAL INSTITUTIONS}

In reflecting back on the mergers that has taken place, one realise the long and sometimes arduous road that have been travelled. It is actually overwhelming to think how much has been achieved in such a short time. Although many people may question the outcomes of some processes, one has to acknowledge the amount of work achieved. If one reflects on whether the merger at the higher education institution where the empirical survey took place, has actually fulfilled the priorities set out in the National Plan of Higher Education (2001), the following can be pointed out:

- To reduce duplication and overlap in programme and service provision.

This aspect could only be addressed to a certain extent and the full benefit of this will only be visible in years to come. There are currently two streams of programmes at the merged institution and it will take some years for these programmes to be combined. The programmes are however combined on a faculty level. On a departmental level, little change has occurred.

- To promote the joint development and delivery of programmes.

This has only been achieved to a certain extent. The two universities that have merged have been fully integrated. There has not yet been much effort in integrating the Technikon stream with the university stream and it will take some time to achieve success in this. Academics delivering these programmes have also been kept separate (those offering University type programmes and those offering Technikon type programmes) to a large extent.

- To help build academic and administrative capacity.

Academics are still trying to understand each other and work through all the changes that have occurred. On many levels, academics are working together, but much development is still needed in this arena. On an administrative level people are also trying to understand each other.

- To refocus and reshape the institutional culture and missions of institutions as South African institutions.

The new university has a new mission and vision and an extensive programme of rolling out the new values was launched. The integration of the cultures is unfolding at a much slower pace. People are experiencing the changes differently and this surely have an impact on creating one institution where all feel welcome. This will take some time to achieve.

\section{ORGANISATIONAL NORMS: A THEORETICAL OVERVIEW}

\section{Concept clarification}

George and Jones (2002:337) define group norms as "informal rules of conduct for behaviour that are considered important by most group members". Dubrin (2007:189) extends this definition by describing group norms as the "guidelines for acceptable and unacceptable behaviours that are informally agreed on by group members". Norms are thus the common standards or ideas which guide member behaviour in all established groups. Although in some instances, norms may be formalised and written (for example, codes of conduct), for the most part, they are unwritten rules concerning those behaviours that are appropriate and acceptable to other group members (Bowditch \& Buono, 1994:171). Norms are also an expression of values. They are the unwritten rules that allow members of a culture to know what is expected of them in a wide variety of situations including how to coordinate their behaviour with that of others (Hatch \& Cunliffe, 2006:187). From the above definitions, a definition of norms should include an understanding of norms as informal rules or standards that guide acceptable and unacceptable behaviours and decide what sanctions should be applied when behaviour does not coincide with social expectations. 


\section{Types of norms}

Norms generally are also enforced only for behaviours that are viewed as most important by most group members (Harvey \& Brown, 2001:12). For Dubrin (2007:189), these norms include behaviours such as: Praising a group member who has just given a presentation at a meeting; not flaunting the use of a competitive product or service; assisting a co-worker who needs your expertise and working on weekends to finish a project if necessary. Various norm types can be found in various settings in life. These include social, business, collaborative and common class norms.

\section{- Social norms}

Kolstad (2007:58) defines social norms as "patterns of behaviour with certain characteristics." Norms communicate expectations regarding many types of social behaviour such as talking in movie theatres, cutting-in lines, and standing at football games (Biel \& Thogersen, 2006:93 and Hatch \& Cunliffe, 2006:87). Norms can also be categorised as descriptive and injunctive norms (Lapinski \& Rimal, 2006:127 and Park \& Smith, 2007:194).

Descriptive norms are concerned with what people actually do. They refer to the perceptions of the most common actions actually exhibited in a social group, such as the quantity and frequency of drinking, and are largely formed from observations of others' alcohol consumption. Park and Smith (cited in Wikipedia, 2008) and Norman, Clark and Walker (2006:1008) found that descriptive norms can be perceived at both a personal and societal level, and regard them as individuals' beliefs regarding the popularity of the behaviour in question, either among valued others or society at large. Injunctive norms are concerned with what people feel is right based on morals or beliefs. White, Smith, Terry, Greenslade and McKimmie (2009:135) regards it as widely shared beliefs or expectations in a social group about how people in general or members of the group ought to behave in various circumstances.

\section{- Business norms}

Business norms communicate important information, for example, when should the boss be informed of potential problems, what sort of clothing should be worn to work, and when it is appropriate to display emotion. While in some organisations these matters are spelled out by formal rules and regulations (a point of overlap between culture and social structure), in most organisations they are left unstated and communicated informally via normative pressures such as disapproving looks or, in some cultures, by looking away (Hatch \& Cunliffe, 2006:187). Harvey and Brown (2001:12) state that norms are essential to accomplishing the organisation's objectives and are called pivotal norms. Norms that support and contribute to the pivotal norms, but that are not essential to the organisation's objectives, are called peripheral norms. Pivotal and peripheral norms constantly confront individuals in an organisation, and they must decide whether or not to conform.

\section{- Collaborative norms}

When norms exist, human behaviour is influenced in accordance with the expectations of the group or community. Norms are also deeply entrenched in organisational culture (Orlikowski, 1993). Norms of collaboration and teamwork can enhance exchange of intellectual capital. It is expected that collaborative norms will have a positive impact on knowledge seeking. Collaborative norms differ somewhat from the norms of team work and broader pro-sharing norms in that pro-sharing norms also include willingness to value and respond to diversity, openness to conflicting views, and tolerance of failure (Leonard-Barton, 1995).

\section{- Common classes of norms}


A work group's norms are like an individual's fingerprints as each is unique (Robbins, 2003:229). Yet there are also common classes of norms that appear in most work groups (Einstein, 2009:63).

- Probably the most common class of norms is performance norms. Work groups typically provide their members with explicit cues on how hard they should work, how to get the job done, their level of output and appropriate levels of tardiness. These norms are extremely powerful in affecting an individual employee's performance as they are capable of significantly modifying a performance prediction that was based solely on the employee's ability and level of personal motivation (Eng, 2006:762 and Robbins, 2003:229).

- A second category of common-class norms encompasses appearance norms. This includes aspects such as appropriate dress, loyalty to the work group or organisation, when to look busy, and when it is acceptable to loaf. Some organisations have formal dress codes, however, even in their absence norms frequently develop to dictate the kind of clothing that should be worn to work. Similarly, presenting the appearance of loyalty is important, especially among professional employees and those in the executive ranks. So it is often considered inappropriate to be openly looking for another job (Strahan, Wilson, Cressman \& Buote, 2006: 211).

- Another common-class norm category concerns social arrangement norms. These norms come from informal work groups and primarily regulate social interactions within the group. For example, with whom group members eat lunch, friendships on and off the job and social games are also influenced by these norms.

- A final category relates to allocation of resources norms. These norms can originate in the group or in the organisation and cover aspects like pay, assignment of difficult jobs, and allocation of new tools and equipment (Endriss, Maudet, Sadri \& Toni, 2006:315 and Robbins, 2003:230).

\section{Purpose of norms}

Moorhead and Griffen (2001:292); Chen, Wasti and Triandis (2007:259) and Kreitner and Kinicki (2008:287) highlight many purposes of norms such as:

- Norms help the group survive. Groups tend to reject deviant behaviour that does not help meet group goals or contribute to the survival of the group if it is threatened. Accordingly, a successful group that is not under threat may be more tolerant of deviant behaviour.

- Norms simplify and make more predictable the behaviours expected of group members. As they are familiar with norms, members do not have to analyse each individual's behaviour and decide on a response. Members can anticipate the actions of others on the basis of group norms, usually resulting in increased productivity and goal attainment.

- Norms help the group avoid embarrassing situations. Group members often want to avoid damaging other members' self-images and are likely to avoid certain subjects that might hurt a member's feelings.

- Norms express the central values of the group and identify the group to others. Certain clothes, mannerisms, or behaviour in particular situations may be a rallying point for members and may signify to others the nature of the group.

\section{Formation of norms}

Group norms usually are established during the second stage of group development (communication and decision making) and carried forward into the maturity stage. Providing a basis for predicting others' behaviours, norms enable members to behave in a manner consistent with and acceptable to the group. Without norms, the activities in a group would be chaotic (Moorhead \& Griffin, 2001:292). Group norms are developed spontaneously as the members interact through the group's routine. As each group member has cultural values and past experience, the group's beliefs, attitudes, and knowledge influence the type of norms developed. For example, the group decides, without ever actually talking about it and agreeing this would be a rule, what is an acceptable level of work. If the group members develop a shared expectation that this level is desirable, members will produce it. In addition the use of certain words or jokes is considered acceptable or not. Norms also change over time to meet the needs of the group (Gruman, Saks \& Zweig, 2006:90 and Lussier, 2003:318). 


\section{- Sources of norms in groups}

Taggar and Ellis (2007:105) highlight the important role of expectations of both group members and leaders in norm formation. Bowditch and Buono (1994:178) identify three primary sources of norms in groups, namely:

- First, the most prevalent source of norms is the group itself. While some norms are explicitly negotiated, most norms emerge implicitly through trial-and-error interaction between group members as different behaviours are tested (storming).

- Second, norms can be influenced by other groups or organisations outside the group in question (for example, charters and chapter by-laws of national or state organisations, professional codes of conduct, industry benchmarking).

- Finally, norms can emerge from the influence of a single member, as when an individual inspires a group to adopt higher standards of behaviour or performance.

\section{- Why group members conform to norms}

Jetten Hornsey and Adarves-Yorno (2006:162) emphasise the role of intragroup status among group members in conforming to group norms, whilst Yao and Wang (2008:247) refer to normative commitment which is linked socially orientated values. George and Jones (2002:339) provide three main reasons for individuals conforming to group norms:

- The first and most widespread basis for conformity to group norms is compliance, assenting to a norm in order to attain rewards or avoid punishment. When members comply with norms, they do not necessarily believe that behaviour specified by the norm is important for its own sake, but they believe that following the norms will bring certain benefits and ignoring it will bring certain costs.

- The second reason for conformity is identification, members associating with supporters of a norm and conforming to the norm because those members do.

- The third and potentially most powerful basis for conformity to group norms is internalisation, believing that the behaviour dictated by the norm is truly the right and proper way to behave. Norms have the most influence on group members when the basis for conformity is internalisation.

\section{INFLUENCE OF DEMOGRAPHICAL FACTORS ON ORGANISATIONAL NORMS}

Dyaram (2005:71) highlights the dynamics of organisational culture and thus the role of organisational norms during the merging of higher education institutions in South Africa. A major challenge is to change the institutional practices, culture, values and norms of the merged institutions into a new culture and the new institution should reflect the wider demographic composition of society. Edgar and Geare (2004:61) are of the opinion that employee demography is often ignored in management research. Lawrence (1997:1) concurs that despite the important role of demography, researchers often leave demographic variables loosely specified and unmeasured. Given a diverse workforce it is reasonable to assume that differences in views and attitudes could exist, which hence justifies examining demographics. Both Greller (1990:4) and Verworn, Schwarz and Herstatt (2009:149) emphasise the challenges of changing workforce demographics on organisational effectiveness. Korac-Kakabadse, Korac-Kakabadse and Myers (1998:351) agree that demographic characteristics such as age, tenure, occupation, gender and ethnicity could influence both organisational dynamics and performance. Group demography thus reflects similarity and dissimilarity amongst individuals which makes it a meaningful perspective for understanding the processes and social context affected by demography. Helms and Stern (2001:415) also explored the demographic factors that influence employee perceptions of organisational processes, culture and social context. Significant differences in perceptions were found between demographical variables such as organisational unit membership, age, gender and ethnicity. 
Based on the above-mentioned reasoning, the following hypotheses were formulated to investigate the relationship between the independent variables (classification or demographical data) and dependent variables (perceptions regarding organisational norms):

$H_{1} \quad$ There is a relationship between organisational norms of males and females.

$\mathrm{H}_{2} \quad$ There is a relationship between organisational norms and the age of respondents.

$\mathrm{H}_{3} \quad$ There is a relationship between organisational norms and the marital status of the respondents.

$\mathrm{H}_{4} \quad$ There is a relationship between organisational norms and the educational level of respondents.

$\mathrm{H}_{5} \quad$ There is a relationship between organisational norms and the administrative section in which respondents are employed.

$H_{6} \quad$ There is a relationship between organisational norms and the whether the respondents' education include administrative subjects.

$\mathrm{H}_{7} \quad$ There is a relationship between organisational norms and the years of service of the respondents.

$\mathrm{H}_{8} \quad$ There is a relationship between organisational norms and the employment status of the respondents.

$\mathrm{H}_{9} \quad$ There is a relationship between organisational norms and the cultural grouping of respondents.

\section{RESEARCH METHODOLOGY}

The following section provides an outline of the methodology followed in this research project

\section{Research paradigm}

According to the positivistic research paradigm, science is value free, is based on facts, relationships and fundamental laws and use quantitative data. (Leedy \& Ormrod, 2005:3). As the research of this project needs to produce data that investigates the norms of an Administrative Department, a quantitative research approach was required, whereby the emphasis is on the quantification of variables and statistical controls. The main purpose (approach) of this research is exploration and description.

\section{Population}

The population for this research project can be regarded as all employees (non-academic) employed in the Academic Administration Department at a higher education institution.

\section{Sampling}

As descriptive research was necessary for describing the organisational norms of the Academic Administrative Department, all 88 persons employed in this section were included in the probability sample. Prior approval was obtained from top management and the Human Ethics Committee to conduct the survey. A total of 51 questionnaires were completed by the respondents (response rate of $58 \%)$.

\section{Data collection}

Data was obtained by means of both secondary and primary data. Various secondary data sources were consulted such as text books, journal articles and the Internet. Primary data was obtained by means of a mail survey using self-administered questionnaires. The main reason for this was the cost involved and accessibility of the respondents. It was also argued that respondents would be ensured anonymity by using a mail survey rather than any other method that would identify the respondents. A covering letter indicating what the research is going to be used for as well as the confidentiality of the answers to the questionnaire was included. The questionnaires were mailed to all staff members in the 
respective sections and an e-mail was also send to the staff members to remind them to complete the questionnaires and return it in a reply envelope.

\section{Questionnaire design}

A validated organisational questionnaire constructed by Alexander (1987) was used in this study to collect data to investigate the organisational norms of the Administrative Department. This questionnaire consists of ten constructs that measure organisational norms in terms of: organisational/personal pride; performance/excellence; teamwork/communication; leadership/supervision; profitability/cost effectiveness; colleague/associate relations; customer/client relations; innovativeness/creativity; training/development and candour/

Openness. This questionnaire is especially suitable for organisational assessment and diagnosis. To ensure that the questionnaire would be understood by the respondents in this survey, a pilot survey was first conducted. The questionnaire was adapted to ensure that the language would be understood and then four staff members (not included in the sample) were requested to complete the questionnaire. It was found that the questions were understood and a few minor changes were affected to the final questionnaire. The questionnaire is divided into three sections, consisting of 55 questions in total, each measuring a particular aspect/construct.

- Section A focused on the biographical/demographical characteristics of the respondents and contains a nominal scale of measurement, using categorical variables. Nine classification data variables were tested. This included: gender, age, marital status, level of education, field of education, section of employment, years of service, employment status and cultural grouping.

- Section B consisted of 42 statements that the respondents had to rate to determine their perception of group norms within the Academic Administration Department. The type of ordinal scale used is by means of semantic differential scaled-response questions according to a fivepoint Likert-type scale ranging from strongly agree or encourage it (1) to strongly disagree with or discourage it (2).

- Section C consisted of three general questions regarding aspects about the Academic Administration Department. One question was based on a nominal scale of measurement investigating which one thing respondents would like to change in their department or section. The other two were open-ended questions (one thing respondents would not like to change and any other comments).

\section{Pilot study}

Although a pre-tested questionnaire was used, attempts were made to ensure that the questionnaire would be understood by the respondents by conducting a pilot survey. The questionnaire was adapted to ensure that the language would be understood and four staff members (not included in the sample) were requested to complete the questionnaire. It was found that the questions were understood and a few minor changes were affected to the final questionnaire

\section{Data analysis}

The questionnaire instrument was pre-coded to assist with preparing the data for statistical analysis. Actual data was entered onto a Microsoft Excel Spreadsheet. All missing variables were coded as 0 . The data was checked for out-of range responses with the descriptive statistics, including frequency distributions, means and ranges. Doubtful data was compared with the questionnaires and all errors were corrected. The data was then ready for analysis and the Statistica (Version 8) Package was used for data analysis. Descriptive statistics was first used to provide a feel for the responses. Thereafter, the responses to the 42 statements that elicited information based on 10 categories on the norms of the respondents were analysed. As a small sample was used, it was not possible to conduct advanced statistics, but T-tests were used to investigate relationships between the various groups of respondents and their perceptions of the norms. The questions in Section $\mathrm{C}$ were coded according to similar themes. 


\section{RELIABILITY AND VALIDITY OF THE RESEARCH}

Struwig and Stead (2001:130) define reliability in quantitative studies as the extent to which test scores are accurate, consistent or stable. A test score's validity is dependent on the score's reliability in that if the reliability is inadequate, the validity will also be poor. It is, therefore, important to determine a score's reliability before the validity is examined. Internal consistency is an index which calculates the extent to which the test items all reflect the same attribute. Internal-consistency comprises the average correlation among the items and the length of the test. In this research project a validated questionnaire was used, as the constructs were tested for reliability and the test scores were found to be reliable. For this test, the Cronbach Alpha was again determined to measure internal-reliability of the instrument scores. The result of the standradised alpha is 0.950023 , indicating internal reliability of the results (alpha $>0.7$ ).

Validity in quantitative research refers the extent to which a research design is scientifically sound or appropriately conducted (Struwig \& Stead, 2001:136). External validity refers to the generalisation of research results to other population groups and is ensured by means of a proper sampling procedure and clear guidelines given regarding the place, time and conditions in which the research was conducted. In this research project, where use was made of a validated questionnaire, specific care was taken to ensure that the questionnaire at least had content and face validity. The internal validity of the instrument's scores is ensured through face validity and content validity - expert judgement (the questionnaire was given to two experts) and a pilot study were undertaken.

\section{EMPIRICAL RESULTS}

\section{Profile of respondents}

Table 1 provides a profile of the respondents based on the categorical variables used in Section A of the questionnaire.

Table $1 \quad$ Frequency distribution results: A respondent profile

\begin{tabular}{|l|l|c|}
\hline Characteristic & Category & (\%) \\
\hline Gender & Male & 18 \\
& Female & 83 \\
\hline Age & $25-34$ & 31 \\
& $35-44$ & 31 \\
& $45-54$ & 28 \\
& $55-64$ & 10 \\
\hline Marital status & Never married & 19 \\
& Not married but living with partner & 4 \\
& First married & 55 \\
& Separated/Divorced & 10 \\
& Remarried & 12 \\
\hline Educational level & Grade 12 or equivalent & 29 \\
& National Certificate or Diploma & 45 \\
& Bachelor's degree & 22 \\
& Post graduate degree & 4 \\
\hline Academic administration & Admissions & 18 \\
section employed & Examinations & 27 \\
& Faculty administration and timetabling & 43 \\
& Student systems and records & 12 \\
\hline Administrative subjects & Yes & 72 \\
completed & No & 20 \\
& Not applicable & 8 \\
& & \\
\hline \multirow{2}{*}{68} & Acta Commercii & \\
& 2009 & \\
\hline
\end{tabular}




\begin{tabular}{|l|l|c|}
\hline Years of service or & $>1$ year & 8 \\
employment & $1-5$ years & 24 \\
& $6-10$ years & 25 \\
& $11-15$ years & 20 \\
& $16+$ & 23 \\
\hline Employment status & Permanent & 92 \\
& Contract & 8 \\
\hline Cultural/ethnic grouping & African & 28 \\
& Coloured & 28 \\
& Indian & 37 \\
& White & 3 \\
\hline
\end{tabular}

The biographical data indicated in Table 1 provides a profile of the respondents of this research project. It is clear that the majority of the respondents were females $(82 \%)$ and are between the ages of 25 to 44 years $(62 \%)$. Fifty-five percent of the respondents were in their first marriage, while $20 \%$ have never been married. All respondents have at least completed grade 12 with $45 \%$ having a National Certificate or Diploma, $22 \%$ completed a bachelor's degree and $4 \%$ graduated with a postgraduate degree. The Faculty Administration and Timetabling section represents the majority of the respondents (43\%) and Examinations section (27\%). Seventy-two percent of the respondents' formal education included administrative subjects while $20 \%$ continued with other types of studies. There is a relatively even spread of years of service between the categories ranging from $1-5(24 \%)$, $6-10(25 \%), 11-15(20 \%)$ and 16 years and more $(24 \%)$. Only $8 \%$ had less than one year of service. The majority of the respondents (92\%) are permanently employed, whilst only $8 \%$ have contract employment. Regarding cultural/ethnic groupings, it appears that the majority of respondents $(63 \%)$ were black, coloured, Indian and other groupings, whilst whites were $27 \%$ of the represented sample.

\section{Descriptive statistics}

Table 2 depicts the results of the frequencies for the perceptions of norms under observation measuring the 10 categories (Section $B$ of the questionnaire).

Table 2 Results of mean scores indicating respondents' perception of norms of the Academic Administration Department

\begin{tabular}{|l|c|c|c|c|c|}
\hline Norms category & Valid N & Mean & Minimum & Maximum & Std.Dev. \\
\hline Teamwork/communication & 51 & 10.90 & 4 & 19 & 3.48 \\
\hline Leadership/supervision & 51 & 10.84 & 5 & 20 & 3.89 \\
\hline Performance/excellence & 51 & 10.67 & 5 & 21 & 4.20 \\
\hline Organisational/personal pride & 51 & 10.16 & 3 & 20 & 3.64 \\
\hline Candour/openness & 51 & 8.86 & 4 & 15 & 3.00 \\
\hline Innovativeness/creativity & 51 & 8.06 & 4 & 17 & 2.90 \\
\hline Profitability/cost effectiveness & 51 & 8.00 & 3 & 17 & 2.87 \\
\hline Training/development & 51 & 7.45 & 2 & 15 & 2.82 \\
\hline Customer/client relations & 51 & 7.24 & 4 & 16 & 2.96 \\
\hline Colleague/associate relations & 51 & 5.29 & 2 & 12 & 2.09 \\
\hline
\end{tabular}

From Table 2, it can be deduced that the staff's perception is that teamwork/communication, leadership/supervision, performance/excellence and organisational/personal pride are very closely ranked with all scores (mean value) above 10. However, candour/openness with a score of 8.86 is followed by innovativeness/creativity and profitability/cost effectiveness with scores of 8.05 and 8.0 respectively. Training/development and customer/client relations scored 7.45 and 7.24 respectively and colleague/associate relations scored 5.29. These last three norms need the most attention and need to be addressed. 
Table 3 highlights the results of Section $\mathrm{C}$ of the questionnaire.

Table 3 General aspects regarding the Academic Administration Department (Section C)

\begin{tabular}{|l|c|l|c|}
\hline Aspects to be changed & $\%$ & One aspect not to be changed & $\%$ \\
\hline Brand & 2 & Teamwork & 34 \\
Equipment & 12 & Communication (internal) & 2 \\
Internal communication & 16 & Floor plan & 2 \\
Office space & 37 & Campus & 14 \\
Services to students & 25 & Working hours & 10 \\
Working hours & 4 & Colleagues & 18 \\
Promotion possibilities & 4 & My office & 2 \\
& & Harmony & 2 \\
& & Management (trust) & 10 \\
\hline Other comments & $\%$ & Co-operation & 2 \\
\hline Happy & 25 & Development & 2 \\
Not happy (de-motivated) & 8 & Interaction with students & \\
\cline { 2 - 3 } & 25 & & \\
Under staffed & 0 & & \\
Staff structure (not satisfactory) & 8 & & \\
Constant service delivery & & & \\
Collegiality needed & 18 & & \\
Positive attitudes needed & 8 & & \\
& 8 & & \\
\hline
\end{tabular}

It is evident that most respondents would like to change their office space $(37 \%)$ and services to students $(25 \%)$. One aspect that respondents did not want to change was teamwork in their sections. The majority other comments that were made were that respondents were happy in their current job $(25 \%)$ and that the multi-campus integration as a result of the merger still needed attention.

\section{T-test statistics}

Table 4 and 5 indicate the results of the T-tests conducted as to establish whether differences observed in the perceptions of norms based on demographical differences of respondents were statistically significant.

Table 4 T-test statistics for establishing relationships between norms of and demographical differences of respondents

\begin{tabular}{|l|c|c|c|c|c|}
\hline Organisational norms & \multicolumn{5}{|c|}{ P-Values of demographical variables } \\
\hline & $\mathbf{1}$ & $\mathbf{2}$ & $\mathbf{3}$ & $\mathbf{4}$ & $\mathbf{5}$ \\
\hline Organisational/personal pride & 0.796965 & 0.531423 & 0.874838 & 0.679005 & 0.134210 \\
\hline Performance/excellence & 0.730473 & 0.099564 & 0.394947 & 0.432476 & $\mathbf{0 . 0 3 3 6 4 6}^{\boldsymbol{*}}$ \\
\hline Teamwork/communication & 0.825571 & 0.876356 & 0.454980 & 0.839271 & $\mathbf{0 . 0 2 8 6 5 0}^{\star}$ \\
\hline Leadership/supervision & 0.956318 & 0.564302 & 0.794849 & 0.739532 & 0.343609 \\
\hline Profitability/cost effectiveness & 1.000000 & 0.313507 & 0.452455 & 0.269132 & $\mathbf{0 . 0 4 3 5 0 8 ^ { * }}$ \\
\hline Colleague/associate relations & 0.951304 & 0.134035 & 0.879898 & 0.934211 & $\mathbf{0 . 0 1 4 4 5 8}^{*}$ \\
\hline Customer/client relations & 0.914223 & $\mathbf{0 . 0 4 2 0 7 1}$ & 0.493825 & 0.137397 & $\mathbf{0 . 0 3 6 4 8 0}^{\star}$ \\
\hline Innovativeness/creativity & 0.974968 & 0.393141 & 0.512211 & 0.954374 & 0.110237 \\
\hline Training/development & 0.791869 & 0.104054 & 0.932617 & 0.555981 & $\mathbf{0 . 0 3 1 7 0 7 ^ { * }}$ \\
\hline Candour/openness & 0.081231 & 0.654859 & 0.752755 & 0.524403 & 0.189437 \\
\hline
\end{tabular}

*Significance at $\mathrm{P}<0.05$

$1=$ Gender

$2=$ Age

$3=$ Marital status

$4=$ Educational Level 


\section{$5=$ Section where employed}

Table 4 clearly indicates that there are no statistically-significant differences in responses between male and female respondents as all P-values are greater than 0.05 . There is only one statisticalsignificant difference in perception in norms by the various age groups when referring to customer/client relations. It appears that there is no statistical-significant difference for any of the categories of norms evaluated based on the respondents marital status. It is also interesting to note that there are no statistical-significant differences in the perceptions of norms of the respondents at the various educational levels. It could easily be assumed that persons of a higher-educational level would perceive situations very differently from persons with a lower-educational level. However, this was not the case in this research project. $\left(\mathrm{H}_{1}\right.$ to $\mathrm{H}_{4}$ rejected). There appears to be a statisticalsignificant difference in the perceptions of staff of the various sections within the Academic Administration Department. It must be noted that performance/excellence, teamwork/communication, profitability/cost effectiveness, colleague/associate relations, customer/client relations and training/development can be identified as the norms where statistical-significant differences exist $(\mathrm{p}<0.05)\left(\mathrm{HO}_{5}\right.$ accepted). The three categories with the lowest mean scores in Table 2 are those categories that need to be addressed and are also part of these categories where statistical-significant differences exist.

Table 5 T-test statistics for establishing relationships between norms of and demographical differences of respondents

\begin{tabular}{|l|c|c|c|l|}
\hline Organisational norms & \multicolumn{4}{|c|}{ P-Values of demographical variables } \\
\hline & $\mathbf{1}$ & $\mathbf{2}$ & $\mathbf{3}$ & \multicolumn{1}{|c|}{$\mathbf{4}$} \\
\hline Organisational/personal pride & 0.560594 & 0.757283 & 0.567010 & 0.750803 \\
\hline Performance/excellence & & & & $\mathbf{0 . 0 4 8 2 2 1}$ \\
& 0.247198 & 0.487068 & 0.488062 & ${ }^{*}$ \\
\hline Teamwork/communication & & & & $\mathbf{0 . 0 1 5 6 2 5}$ \\
& 0.378774 & 0.516997 & 0.258219 & ${ }^{*}$ \\
\hline Leadership/supervision & 0.584172 & 0.204593 & 0.749405 & 0.120959 \\
\hline Profitability/cost effectiveness & 0.252281 & 0.153745 & 0.848181 & 0.137738 \\
\hline Colleague/associate relations & & & & $\mathbf{0 . 0 0 4 7 9 1}$ \\
& 0.552480 & 0.927085 & 0.209106 & ${ }^{*}$ \\
\hline Customer/client relations & & & & $\mathbf{0 . 0 0 0 1 9 5}$ \\
\hline Innovativeness/creativity & 0.270136 & 0.811642 & 0.611320 & ${ }^{*}$ \\
\hline Training/development & 0.783395 & 0.471762 & 0.134686 & 0.063218 \\
\hline Candour/openness & & & & $\mathbf{0 . 0 0 2 1 8 1}$ \\
& 0.315847 & 0.708776 & 0.389659 & ${ }^{*}$ \\
\hline
\end{tabular}

${ }^{*}$ Significance at $\mathrm{P}<0.05$

$1=$ Administration subjects included studies

$2=$ Years of service

$3=$ Employment status

$4=$ Cultural/ethnic grouping

Table 5 shows that that there is no statistical-significant difference in perceptions based on the subject content of the higher education received. It also appears that there is no statistical-significant difference in the perceptions of respondents with various years of service with regards to any of the categories. No statistical-significant difference with regards to responses from persons with different employment status exists $\left(\mathrm{H}_{6}\right.$ to $\mathrm{H}_{8}$ thus rejected). Based on cultural/ethnic groupings, there are a number of categories that are statistically-significantly different. These categories are performance/excellence, teamwork/communication, colleague/associate relations, customer/client relations, training/development and candour/openness $\left(\mathrm{HO}_{9}\right.$ accepted). If one uses the individual variables of organisational norms and the statistical relationships established in Table 4 and 5 , then a 
hypothetical model can be developed. Figure 1 indicates the relationships between the independent and dependent variables and suggest a hypothetical model that can be used in future research.

Figure 1 outlines the possible relationships to investigate in future research. It is clear that the most statistical significant relationships (7) were found among various cultural groupings followed by the section in which the person is employed (6 statistical significant relationships). In contrast only one variable had a statistical significant relationship with the age of the respondents, namely customer/client relations. Independent variables such as sex, marital status, educational level, whether administration subjects were included in the studies, years of service and employment status showed no statistical relationships with the variables that make up the norms of the organisation.

\section{Figure 1: Relationships between the independent and dependent variables and testing of hypotheses}

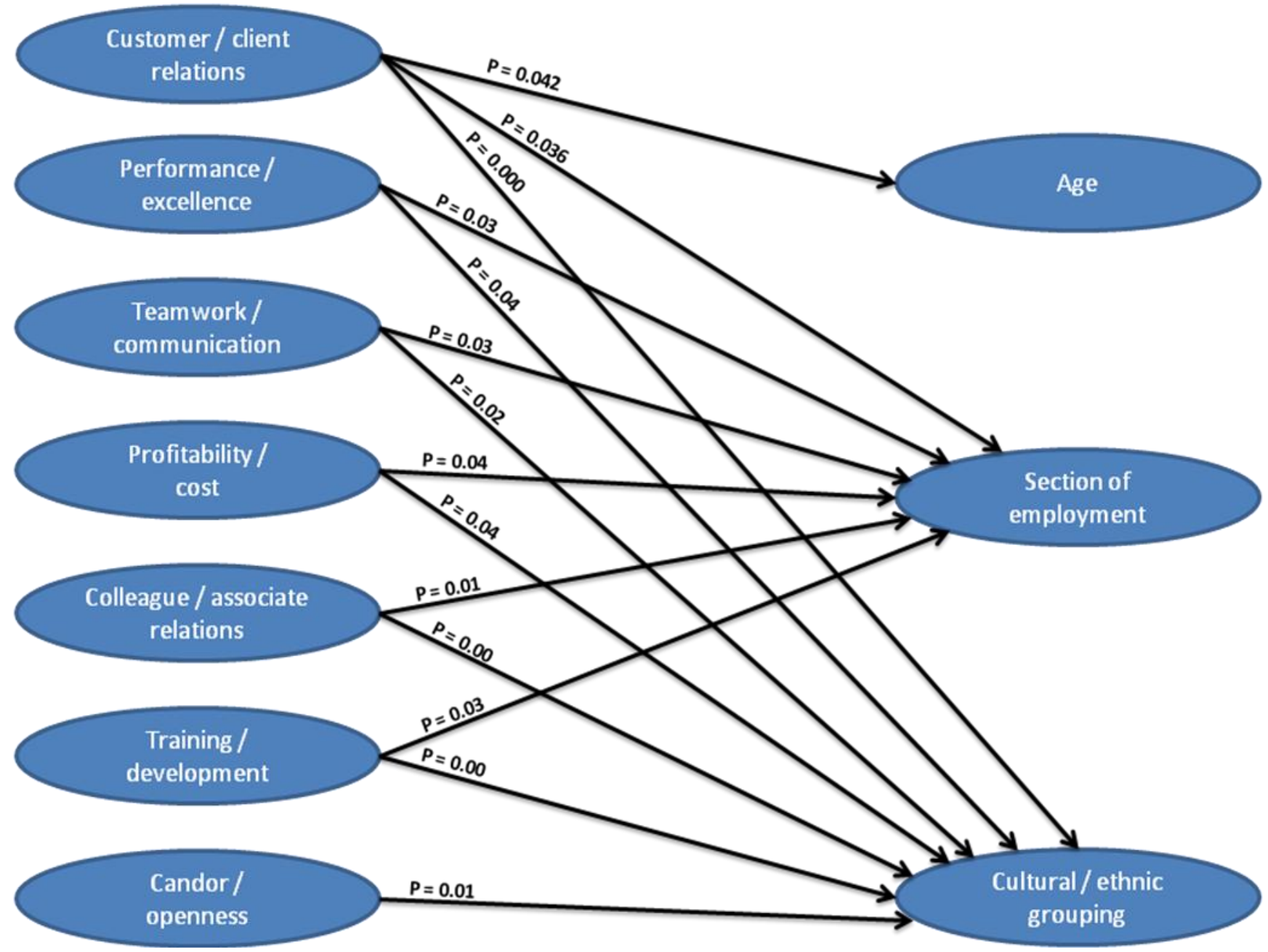




\section{CONCLUSIONS AND RECOMMENDATIONS}

The following conclusions and recommendations can be identified, based on the results of the T-tests:

- There appears to be a significant relationship between the age levels of respondents only in the variable of customer/client relations as an organisational norm. Respondents of various age groups have different perceptions regarding customer/client relations as an organisational norm. This organisational norm should be important to every employee, irrespective of age. This was also one of the norms identified by respondents that seem to be problematic and need interventions. Although it appears that employees from different age groups have different perceptions toward customer/client relations, it is recommended that organisations should attempt to foster a service culture among all employees.

- Organisational members employed in different sections of the Academic Administration Department have different perceptions regarding the following organisational norms: performance excellence; teamwork/communication; profitability/cost; colleague/associate relations; customer/client relations and training/development. Employees in the various sections of this department differ in terms of their views regarding the afore-mentioned organisational norms. Three of these organisational norms were also identified as being problematic and need interventions (training/development; customer/client relations and colleague/associate relations). Organisational interventions should be aimed at: motivating employees to attend training and development programmes and to take responsibility for self-development; fostering a service culture and effective relationships among fellow employees. Organisational members employed in various sections seem to be indifferent towards the following norms: leadership/supervision; organisational pride; candour/openness and innovativeness/creativity.

- There appears to be a significant relationship between employees form various cultural/ethnic groups and the following organisational norms: performance excellence; teamwork/communication; colleague/associate relations; customer/client relations; training/development and candour/openness. Interventions aimed at fostering these organisational norms should thus be ethnic sensitive. Once again the three norms (training/development; customer/client relations and colleague/associate relations) that appear to be problematic and need interventions are mentioned above. Employees from various ethnic groups appear to be indifferent toward the following norms: leadership/supervision; organisational/personal pride; innovativeness/ creativity and profitability/cost.

The following organisational norms are acceptable in this academic administration department and need to be maintained:

- Teamwork/communication - employees seem to be working together as teams and the communication is effective.

- Leadership/supervision - employees seem to accept the leadership in their sections.

- Performance/excellence - employees seem to understand what is required from them in terms of performance and what excellence entails.

- Organisational/personal pride - employees seem to be proud to work in the section that they do.

The following norms are not problematic yet, but could pose various challenges:

- Candor/openness - employees seem not to feel comfortable being open and talking freely about problems in their section.

- Innovativeness/creativity - employees seem to not want to give new ideas.

- Profitability/cost effectiveness - employees seem not to feel responsible for reducing costs.

The following norms are problematic and need interventions:

- Training/development - employees seem to lack motivation to attend programmes to develop themselves.

- Customer/client relations - employees seem to lack a service culture. 
- Colleague/associate relations - employees seem to lack effective relationships with their fellow employees.

Some proposals to address the three categories of norms that need interventions are:

- Training and development

Employees need to be motivated to develop themselves. The reasons why employees do not want to attend training sessions needs to be investigated. Two possible reasons could be a lack of finance and lack of time to attend.

- Customer/client relations

To be customer-focused needs specific interventions and it is proposed that the Administrative Department pursue the various options available in this regard.

- Colleagues/associate relations

The multi-campus situation poses various challenges with regard to fellow employees having enough time to get to know each other. Specific effort needs to be taken to ensure that employees have time to get to know each other and to understand the environment in which the employees operate.

Respondents further indicated that the one aspect that they would like to change in their section is office space. The one aspect that they would not like to change was teamwork, and, under general comments, the employees indicated that they were happy in their job and also that multi-campus integration has not been effective.

Table 6 provide a checklist or guidelines of organisational norms to be nurtured by organisations (based on the questionnaire used in the empirical study). These norms could be used when new groups or working relationships are established in an organisation.

\section{Table 6: Guidelines for nurturing organisational norms}

\begin{tabular}{|l|l|}
\hline Colleague/associate norms & Organisational/personal pride norms \\
\hline Not taking advantage of a fellow employee & Criticize the organisation and the people in it \\
\hline $\begin{array}{l}\text { Express concern for the well-being of other } \\
\text { members of the organisation }\end{array}$ & $\begin{array}{l}\text { Show concern for the problems that face the } \\
\text { organisation and make suggestions about } \\
\text { solving them }\end{array}$ \\
\hline $\begin{array}{l}\text { Make an effort to get to know the people } \\
\text { he/she works with }\end{array}$ & Talk about work with satisfaction \\
\hline Customer/client norms & Profitability/cost norms \\
\hline $\begin{array}{l}\text { Not keep a customer/client waiting in order to } \\
\text { look after matters of personal convenience }\end{array}$ & $\begin{array}{l}\text { Evaluate expenditures in terms of the } \\
\text { benefits they will provide for the organisation }\end{array}$ \\
\hline $\begin{array}{l}\text { Attempt to find new and better ways to serve } \\
\text { the customer/client }\end{array}$ & $\begin{array}{l}\text { Look upon himself/herself as being } \\
\text { responsible for reducing costs }\end{array}$ \\
\hline $\begin{array}{l}\text { Not see the customer/client as a burden or } \\
\text { obstruction to getting the job done }\end{array}$ & $\begin{array}{l}\text { Not purposely misuse equipment or } \\
\text { privileges }\end{array}$ \\
\hline Candour/openness norms & Performance/excellence norms \\
\hline $\begin{array}{l}\text { Talk freely and openly about the organisation } \\
\text { and its problems }\end{array}$ & $\begin{array}{l}\text { Set very high personal standards of } \\
\text { performance }\end{array}$ \\
\hline $\begin{array}{l}\text { Suggest confronting the boss about a } \\
\text { mistake or something in the boss's style that } \\
\text { is creating problems }\end{array}$ & $\begin{array}{l}\text { Try to improve things even though the } \\
\text { operation is running smoothly }\end{array}$ \\
\hline $\begin{array}{l}\text { Talk openly about problems facing the work } \\
\text { group }\end{array}$ & $\begin{array}{l}\text { Suggest that employees should do only } \\
\text { enough to get by }\end{array}$ \\
\hline Innovativeness/creativity & Teamwork/communication norms \\
\hline $\begin{array}{l}\text { Suggest a new idea or approach for doing } \\
\text { things }\end{array}$ & Listen to others and try to get their opinions \\
\hline $\begin{array}{l}\text { Attempt to experiment in order to do things } \\
\text { better in the work situation }\end{array}$ & $\begin{array}{l}\text { Go out of his/her way to help other members } \\
\text { of the work group }\end{array}$ \\
\hline Think of going to the boss with an idea or & Try to make the work group operate more like \\
\hline
\end{tabular}




\begin{tabular}{|l|l|}
\hline Colleague/associate norms & Organisational/personal pride norms \\
\hline suggestion & a team when dealing with issues or problems \\
\hline Leadership/supervision norms & Training/development norms \\
\hline $\begin{array}{l}\text { Look upon the supervisor as a source of help } \\
\text { and development }\end{array}$ & $\begin{array}{l}\text { Show enthusiasm for going to a sponsored } \\
\text { training program }\end{array}$ \\
\hline $\begin{array}{l}\text { Look upon the supervisor as someone to talk } \\
\text { openly and freely to }\end{array}$ & $\begin{array}{l}\text { Talk about what training he/she should get in } \\
\text { order to do a better job }\end{array}$ \\
\hline $\begin{array}{l}\text { Do his/her job even when the supervisor is } \\
\text { not around }\end{array}$ & $\begin{array}{l}\text { Actively look for ways to expand his/her } \\
\text { knowledge in order to be able to do a better } \\
\text { job }\end{array}$ \\
\hline
\end{tabular}

The following extract seems to be appropriate to conclude this article:

"Effective organisational change is therefore likely to be achieved when it is in line with the organisational paradigm and the cultural, social and political norms of organisational life. The problems begin when radical change attempts to take people away from the 'core beliefs' - the way we do things around here. Before any redesign of teaching and learning can be considered inefficiencies and fragmented administrative management must be addressed ... and the potential has to be matched against the cultural and structural factors within higher education institutions..." (Allen \& Fifield, 1999).

\section{LIST OF REFERENCES}

Allen, D.K. \& Fifield, N. 1999. Re-engineering change in higher education. Information Research (An International Electronic Journal). 4(3).

Biel, A. \& Thogersen .J. 2007. Activation of social norms in social dilemmas: A review of the evidence and reflections on the implications for environmental behaviour. Journal of Economic Psychology. 28(1). 93-112.

Biloslovo, R. \& Trnavcevic, A. 2007. Knowledge management audit in a higher education institution: A case study. Knowledge and Process Management. 14(4). 275-286.

Bowditch, J. L., \& Buono, A. F. (1994). A Primer on Organizational Behavior. New York: John Wiley and Sons, Incorporated.

Bray, N.J. 2008. Prospective norms for academic deans: Comparing faculty expectations across institutional and disciplinary boundaries. The Journal of Higher Education. 79(6). 692-721.

Broersen, B. \& Van der Torre, L. 2009. Reasoning about norms, obligations, time and agents. Lecture Notes in Computer Science. 5044. 171-182.

Chen, X., Wasti, S.A. \& Triandis, H.C. 2006. When does group norm of group idenmtity predict cooperation in a public goods dilemma? The moderating effects of idiocentrism and allocentrism. International Journal of Intercultural Relations. 31(2). 259-276.

Department of Education. 1996. Greenpaper, Pretoria: Government Printers.

Dubrin, A. J. (2007). Fundamentals of Organizational behavior. Mason: Thomson South-Western.

Dayaram, K. 2005. Navigating complexity: The dynamics of organizational culture during a merger. Research and Practice in Human Resource Management, 13(1). 71-84.

Edgar, F. \& Geare, A. 2004. Employee demographics in human resource management research. Research and Practice in Human Resource Management, 12(1). 61-91.

Education White Paper. (1997). Nr 3: A programme for the transformation of Higher Education, July, Pretoria: Government Printers. 
Einstein, A. 2009. Organizational performance in a nutshell. New York: Anchor Books.

Endris, U., Maudet, N., Sadri, F. \& Toni, F. 2006. Negotiating socially optimal allocation of resources. Journal of Artificial Intelligence Research. 25. 315-348.

Eng, T. 2006. An investigation into the mediating role of cross-functional coordination on the linkage between organizational norms and SCM performance. Industrial Marketing Management. 35(6). 762-773.

George, J. M., \& Jones, G. R. (2002). Organizational Behavior. New Jersey: Prentice-Hall International.

Government Gazette. 2002. Nr 23549. Published 21 June 2002. Pretoria: Government Printers.

Greller, M.M. 1990. The changing workforce and organisation effectiveness: An agenda for change. Journal of Organizational Change Management, 3(2). 4-15.

Gruman, J.A., Saks, A.M. \& Zweig, D.I. 2006. Organizational socialization tactics and newcomer proactive behaviors: An integrative study. Journal of Vocational Behavior. 69(1). 90-104.

Harvey, D., \& Brown, D. R. (2001). An Experiential Approach to Organization Developement. New Jersey: Prentice Hall.

Hatch, M. J., \& Cunliffe, A. L. (2006). Organization Theory: Modern, Symbolic, and Postmodern Perspectives. New York: Oxford University Press.

Houston, D. 2008. Rethinking quality and improvement in higher education. Quality Assurance in Education. 16(1). 61-79.

Jetten, J., Hornsey, M.J. \& Adarves-Yorno, I. 2006. When group members admit to being conformist: The role of relative intragroup status in conformity self-reports. Personality and Social Psychology Bulletin. 32(2). 162-173.

Jongbloed, B., Enders, J. \& Salerno, C. 2008. Higher education and its communities: Intercommunity interdependencies and a research agenda. Journal of Higher Education. 56(3). 303-324.

Kolstad, I. 2007. The evolution of social norms: With managerial implications. Journal of SocioEconomics. 36(1). 58-72.

Korac-Kakabadse, A., Korac-Kakabadse, N. \& Myers, A. 1998. Demographics and leadership philosophy: Exploring gender differences. Journal of Management Development, 17(5). 351-388.

Kreitner, R. \& Kinicki, A. 2008. Organizational behaviour. Boston: McGraw-Hill Irwin.

Lapinski, M.K. \& Rimal, R.N. 2006. An explication of social norms. Communication Theory. 15(2). 127-147.

Lawrence, B.S. 1997. The black box of organizational demography. Organizational Science, 8(1). 122.

Leedy, P. D., \& Ormrod, J. E. (2005). Practical Research: Planning and Design. Upper Saddle River: Pearson, Merrill Prentice Hall.

Lussier, R. N. (2003). Management Fundamentals: Concepts, Applications, Skills Development. Mason: Thomas, South-Western. 
Moorhead, G., \& Griffin, R. W. (2001). Organizational Behavior: Managing People and Organizations. Boston: Houghton Mifflin Company.

National Plan for Higher Education. (2001). Ministry of Education and Home Affairs. Pretoria: Government Printers.

Norman, P., Clark, T. Walker, G. 2006. The theory of planned behaviour, descriptive norms and the moderating role of group identification. Journal of Applied Social Psychology. 35(5). 1008-1029.

Park, H.S. \& Smith, S.W. 2006. Distinctiveness and influence of subjective norms, personal descriptive and injunctive norms, and societal descriptive and injunctive norms on behavioural intent: A case of two behaviors critical to organ donation. Human Communication Research. 33(2). 194218.

Robbins, S. P. (2003). Organizational Behavior. New Jersey: Prentice Hall.

Schultz. H. (Editor). 2006. Organisational behaviour: A contemporary South African perspective. Pretoria: Van Schaik.

Strahan, E.J., Wilson, A.E. Cressman, K.E. \& Buote, V.M. 2006. Comparing to perfection: How cultural norms for appearance affect social comparisons and self-image. Body Image. 3(3). 211-227.

Struwig, F. W., \& Stead, G. B. (2001). Planning, designing and reporting research. Cape Town: Pearson Education South Africa.

Taggar, S. \& Ellis, R. 2007. The role leaders in shaping formal teams norms. The leadership Quarterly. 18(2). 105-120.

Umashankar, V. \& Dutta, K. 2007. Balanced scorecards in managing higher education institutions: An Indian perspective. International Journal of Educational Management. 21(1). 54-67.

Verworn, B., Schwarz, D. \& Herstatt, C. 2009. Changing workforce demographics: Strategies derived from the resource-based view of HRM. International Journal of Human Resource Development and Management, 9(2-3). 149-161.

White, K.M., Smith, J.R., Greenslade, J.H. \& McKimmie, B.M. 2009. Social influence in the theory of planned behaviour: The role of descriptive, injunctive and in-group norms. $\quad 48.135-158$.

Yao, X. \& Wang, L. 2008. Socially orientated values and reciprocity norms predict organizational commitment. Asian Journal of Social Psychology. 11(3). 247-252.

Acknowledgement: Chantal Van Heerden who has conducted the empirical survey for this study. 